\title{
Optic atrophy-intellectual disability syndrome
}

INSERM

\section{Source}

INSERM. (1999). Orphanet: an online rare disease and orphan drug data base. Optic atrophy-intellectual disability syndrome. ORPHA:401777

Optic atrophy-intellectual disability syndrome is a rare, hereditary, syndromic intellectual disability characterized by developmental delay, intellectual disability, and significant visual impairment due to optic nerve atrophy, optic nerve hypoplasia or cerebral visual impairment. Other common clinical signs and symptoms are hypotonia, oromotor dysfunction, seizures, autism spectrum disorder, and repetitive behaviors. Dysmorphic facial features are variable and nonspecific. 